\title{
Characterization of Dexamethasone-eluting PLGA Films Coated on Capsular Tension Ring to Prevent Posterior Capsule Opacification
}

\author{
Byung Kon Chang, Bo Gyun Kım, Young Jae Kım, Myung Joo KanG, \\ Jaehwi LEE*, and Young Wook CHOI* \\ Division of Pharmaceutical Sciences, College of Pharmacy, Chung-Ang University, Seoul 156-756, Republic of Korea
}

(Received October 7, 2008; Revised October 8, 2008; Accepted Novemver 17, 2008)

\begin{abstract}
The objectives of this study were to prepare PLGA film onto the surface of the capsular tension ring (CTR) for controlled drug release and investigate the influence of plasticizers, the test drug and measurement conditions on flexibility of the film. Film solutions were prepared by dissolving PLGA, plasticizer (triethyl citrate, TEC or polyethylene glycol, PEG), test drug (dexamethasone) in ethyl acetate then films were prepared by spray coating and evaporation method. Then, the flexibility of PLGA film was determined by elongation test. The addition of plasticizer, PEG or TEC to PLGA copolymer caused a depression of glass transition temperature $\left(T_{\mathrm{g}}\right)$ and the elasticity of PLGA films increased. The addition of dexamethasone to the PLGATTEC matrix decreased the flexibility of film. Dimensional factors of the PLGA films such as width and thickness were significantly influenced on flexibility of films and film length and elongation speed had no considerable influence on elongation of films. In this study, sufficiently flexible and stable PLGA films capable of being coated onto CTR could be prepared. This PLGA films can be used as a platform for local drug delivery.
\end{abstract}

Keywords: PLGA film, Capsular tension ring, Flexibility, Plasticizer, Elongation test

\section{INTRODUCTION}

Posterior capsule opacification (PCO) is a major complication of cataract surgery occurring in 15 to $50 \%$ of the treated eyes following 3 to 5 years of the surgery (Bertelmann and Kojetinsky, 1995). It is caused by migration and proliferation of residual equatorial lens epithelial cells (LECs) to intraocular lens after cataract surgery resulting in significant visual impairment (Fernandez et al., 2004).

The prevention of PCO is one of the big challenges in ophthalmic treatment because of the medical and financial implication and localized drug delivery to residual equatorial LECs is believed to be the optimal approach for the prevention of PCO. Several experimental studies using intraocular infusion of drugs such as colchicine, methotrexate, retinoic acid, 5-fluorouracil and dexamethasone have been performed in animal models to prevent

\section{${ }^{*}$ Corresponding author}

Tel: +82-2-820-5606 (JL), +82-820-5609 (YWC),

Fax: +82-2-816-7338 (JL), +82-2-826-3781 (YWC)

E-mail: jaehwi@cau.ac.kr, ywchoi@cau.ac.kr
PCO (Ruiz et al., 1995; Tetz et al., 1995; Ismail et al., 1996; Legler et al., 1993; Power et al., 1994).

CTR assists the cataract surgeon to have weak zonules and centers an intraocular lens. To prevent PCO, drug-eluting CTR has been developed as one of the PCO therapies (Apple et al., 2000; Pandey et al., 2002; Peng et al., 2000a, 2000b). In this study, we designed poly(lactic-co-glycolic acid) (PLGA) films on CTR, horseshoeshaped open ring with $0.1-0.3 \mathrm{~mm}$ thickness as a drug delivery platform. Film formulations based on an FDA approved biocompatible and biodegradable copolymer PLGA have been used for the controlled release of a number of different drugs (Dorta et al., 2002; Gumusderelioglu et al., 2000). Since PLGA film is brittle without any additives, the formation of physically stable PLGA films onto CTR having a big curvature seems to be very difficult. Thus, to deliver drugs from PLGA film formed on CTR for the prevention of PCO it is essential to produce flexible films capable of staying firmly on CTR.

It is well known that the addition of plasticizers such as polyethylene glycol (PEG) and triethyl citrate (TEC) causes a depression of glass transition temperature and 
thereby makes the film flexible (Kranz et al., 2000; Webber et al., 1998). Thus, the objectives of this study were to prepare of PLGA film with plasticizers to give flexibility and dexamethasone, a model drug, coated onto CTR and evaluate the physical properties of the PLGA film by investigating the influence of plasticizers, the test drug and measurement conditions on flexibility of the film. Film flexibility was evaluated by measuring the elongation properties of the PLGA films.

\section{MATERIALS AND METHODS}

\section{Materials}

PLGA with weight percentages of lactic acid to glycolic acid of 50:50 (molecular weight $57800 \mathrm{~g} / \mathrm{mol}$ ), polyethylene glycol (PEG) having molecular weight of $300 \mathrm{~g} / \mathrm{mol}$, and triethyl citrate (TEC) were obtained from Sigma-Aldrich Company (MO, USA). Dexamethasone was supplied by Tokyo Chemical Industry (Tokyo, Japan). All solvents were HPLC grade and obtained from Fisher Scientific (NJ, USA).

\section{Solvent screening}

Selecting a solvent with an ability to solubilize PLGA and no interaction with CTR made of polymethyl methacrylate is important in the production of films onto CTR. A variety of organic solvents were screened for the solubilizing ability of PLGA based on the information reported (Table 1) (Brodbeck et al., 1999; Ferruti et al., 1995) and an interaction between solvents and CTR was evaluated by microscopic inspection.

\section{Preparation of PLGA films onto CTR}

Film compositions in solution were made by dissolving an appropriate amount of polymers (i.e., PLGA contain-

Table I. Properties of organic PLGA solvents

\begin{tabular}{ccc}
\hline & $\begin{array}{c}\text { Boiling points } \\
\left({ }^{\circ} \mathrm{C}\right)\end{array}$ & $\begin{array}{c}\text { Solubility parameter } \\
\text { MPa }^{1 / 2}\end{array}$ \\
\hline Methylene chloride & 40 & 18.5 \\
Ethyl acetate & 77 & 17.6 \\
Acetic acid & 118 & 20.7 \\
Dimethyl sulfoxide & 189 & 24.5 \\
N-methyl 2-Pyrrolidinone & 202 & 23.1 \\
Ethyl bebzoate & 212 & 23.1 \\
Triacetin & 258 & - \\
Benzyl benzoate & 323 & - \\
\hline
\end{tabular}

ing PEG or TEC) and dexamethasone in $1 \mathrm{ml}$ of ethyl acetate to obtain a film former concentration of $1 \% \mathrm{w} / \mathrm{v}$. The solutions were allowed to stand with stirring for approximately $1 \mathrm{~h}$ until visually clear. To form PLGA films onto CTR, the polymer solution was directly sprayed onto CTR from a distance of $5 \mathrm{~cm}$ using an airbrush (Model Spray-Work HG Super Fine Double Action Airbrush, Tamiya, Japan) and dried for 2 days at room temperature. When PLGA thin films were needed for the study of mechanical properties of the films, PLGA films were prepared by spraying the polymer solutions on a flat surface $(1.0 \times 1.0 \mathrm{~cm})$ of silicone and evaporating the solvent.

\section{Differential scanning calorimetry (DSC)}

DSC was performed using a Mettler Toledo Stare calorimeter. Approximately $10 \mathrm{mg}$ of PLGA films were placed in a crimped aluminum DSC pan. Then DSC curves of each film were obtained from the second heating run at a rate of $10^{\circ} \mathrm{C} / \mathrm{min}$, after the first run of heating up to 100 ${ }^{\circ} \mathrm{C}$ and cooling to $0{ }^{\circ} \mathrm{C}$ at the same rate of $10^{\circ} \mathrm{C} / \mathrm{min}$, under nitrogen atmosphere, in order to estimate the glass transition temperature.

\section{Flexibility of PLGA films}

The flexibility of films was evaluated through an elongation test. Square films of $1.0 \mathrm{~cm} \times 1.0 \mathrm{~cm}$ with a thickness of $0.01 \mathrm{~mm}$, were carefully placed between the two vertical grips. The thickness of the film was measured using a digital microscope VHX-100 (Kyence, UK). The movable grip was then driven upward with a speed of 10 $\mathrm{mm} / \mathrm{min}$ until the rupture of the film. Percent elongation at break $(\varepsilon)$ was calculated with the following equation:

$$
\varepsilon(\%)=\frac{\mathrm{L}_{\mathrm{R}}}{\mathrm{L}_{\mathrm{o}}} * 100
$$

where $L_{R}(\mathrm{~mm})$ is the extension of the sample in the moment of rupture and $L_{0}(\mathrm{~mm})$ is the original sample length. Each experiment was repeated five times.

\section{Plasticizer effect on film flexibility}

To examine the influence of increasing amounts of PEG or TEC in PLGA films on the flexibility of the films, the elongation properties of PLGA films containing $0.5,1$, 2 , and $5 \%(\mathrm{w} / \mathrm{w})$ of TEC or PEG were evaluated as previously described.

\section{Drug effect on film flexibility}

To test the influence of increasing amounts of dexamethasone in PLGA films on the flexibility of the films, the elongation properties of PLGA films containing 1, 2, and 
$5 \%(\mathrm{w} / \mathrm{w})$ of dexamethasone were evaluated as previously described.

\section{Impact of film length, width, thickness and elonga- tion speed on film flexibility}

To examine the influence of the film length, width and thickness on the flexibility, PLGA films having different lengths (i.e., 1, 2, and $3 \mathrm{~cm}$ ), different widths $(0.5,1$ and $2 \mathrm{~cm}$ ) and three different thicknesses $(10,20$ and $30 \mu \mathrm{m})$ were prepared and measured for their elongation properties. And three different speeds of $5 \mathrm{~mm} / \mathrm{min}, 10 \mathrm{~mm} / \mathrm{min}$ and $20 \mathrm{~mm} / \mathrm{min}$ were employed during the measurements to see how the elongation speeds influence the measurement results.

\section{Mechanical stability of PLGA films formed onto CTR}

As previously described, a polymer solution of $1 \%(\mathrm{w} /$ v) in ethyl acetate was sprayed onto CTR from a distance of $5 \mathrm{~cm}$ using an air brush and dried for 2 days at room temperature. The PLGA films composed of PLGA : TEC: dexamethasone $=93: 5: 2$. The surface morphology of the films was observed using a digital microscope (VHX-100, Kyence, UK) right after the CTR was stretched and bended ten times.

\section{RESULTS AND DISCUSSION}

Among the solvents screened (Table 1), the solvents with a low boiling point, for instance $<100$, would be a good candidate because it will take little time for the solvent to be evaporated. In this regard, methylene chloride and ethyl acetate were selected as they have lower boiling points. Additionally, to check the interaction of CTR with these two solvents, it was immersed in ethyl acetate or methylene chloride and microscopically observed for any morphological changes of CTR. As a result of the immersion test, ethyl acetate was found to be a suitable solvent for the production of PLGA solutions.

Film solutions were prepared by dissolving PLGA, plasticizer (TEC or PEG) and dexamethasone in ethyl acetate. Then homogeneous PLGA film solutions were efficiently sprayed onto CTR using an airbrush and dried at room temperature.

The PLGA films showed a glass transition temperature $\left(T_{\mathrm{g}}\right)$ of 42.3 and were brittle in the absence of plasticizers. DSC scans for PLGA polymers with plasticizers showed a single $T_{\mathrm{g}}$. The addition of PEG or TEC to PLGA copolymers caused a concentration dependent decrease in $T_{\mathrm{g}}$ values of the PLGA films (Figure 1). Indeed, the addition of increasing amounts of TEC or
PEG to PLGA up to $5 \%$ by weight produced a concentration dependent decrease in $T_{\mathrm{g}}$ of the blended polymer. These lowered $T_{\mathrm{g}}$ should lead to an increased film flexibility. PLGA films made from PLGA alone were fairly brittle when the elongation stress was applied. The addition of either PEG or TEC to the PLGA films resulted in an increase in the elasticity and flexibility of the films. The addition of increasing amounts of PEG or TEC to the PLGA films increased the elongation force as shown in Figure 2. This can greatly be attributed to the role of plasticizers which generally increase the flexibility of polymers.

The addition of dexamethasone at concentrations of 1 , 2 and $5 \%(\mathrm{w} / \mathrm{w})$ caused a concentration dependent decrease in the elasticity of these films as shown in Figure 3. The decrease in elasticity measurements caused by the addition of dexamethasone to the PLGA/TEC matrix may have been due to antiplasticization effect of drug and strong intermolecular interactions between the

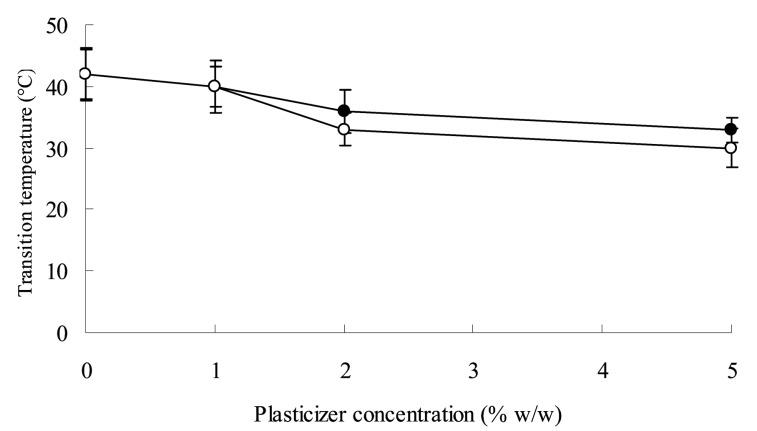

Fig. 1. Effect of blending of TEC or PEG into PLGA films on the glass transition temperature $\left(T_{\mathrm{g}}\right):(\mathbf{O})$, TEC; $(\bigcirc)$, PEG (Mean \pm S.D., $n=5$ ).

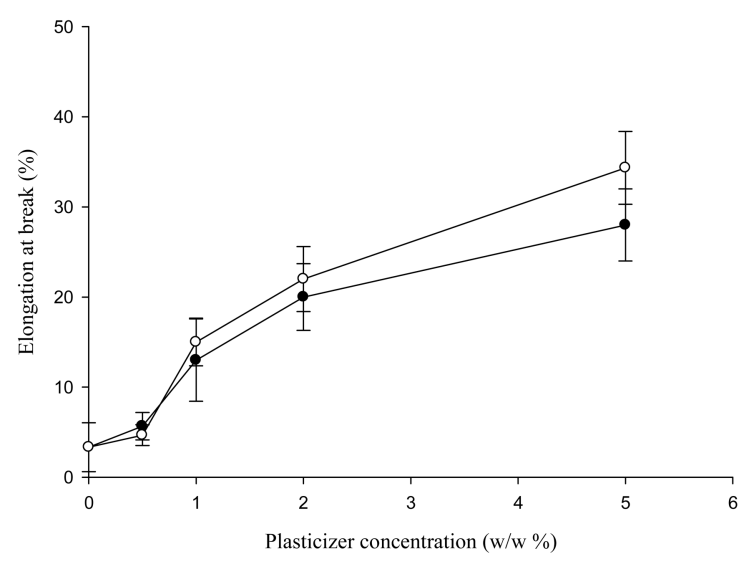

Fig. 2. Effect of plasticizer concentration on the elastic property of the PLGA films : (O), TEC; (O), PEG (Mean \pm S.D., $n=5)$. 


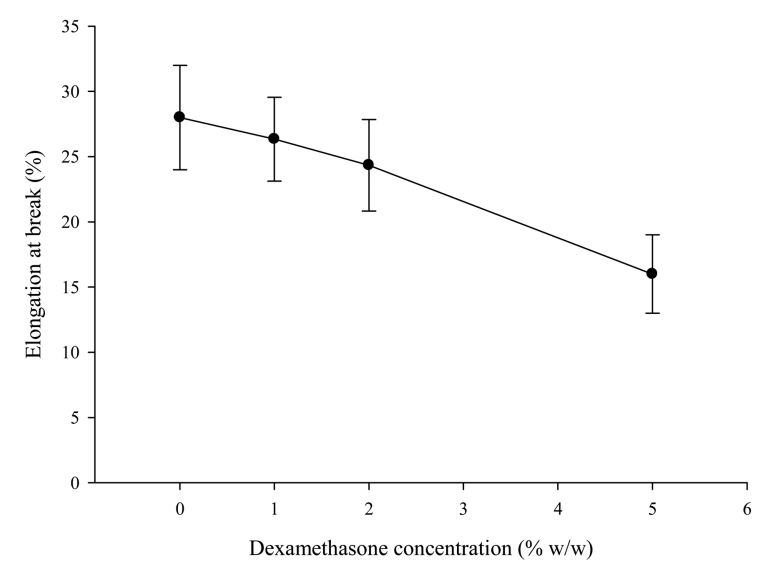

Fig. 3. Effect of dexamethasone concentration on the elastic property of the PLGA films (Mean \pm S.D., $n=5$ ).

drug and the polymer (Webber et al., 1998).

For the evaluation of elongation properties of PLGA films, various dimensional factors of the PLGA films and measurement condition such as elongation speed were examined. The increase in film length and elongation speed had no considerable influence on elongation force as shown in Figure 4 and Figure 7, respectively. However, the width and thickness of film significantly influenced on elongation properties of the films and showed bigger differences in elongation properties than length or elongation speed as shown in Figure 5 and Figure 6, respectively. With the increment of film width and thickness, the elongation at break (\%) was increased.

The polymer matrix should have good mechanical properties in terms of flexibility and long lasting adherence to the CTR surface at the required size when the device is deployed. Morphological features of PLGA films

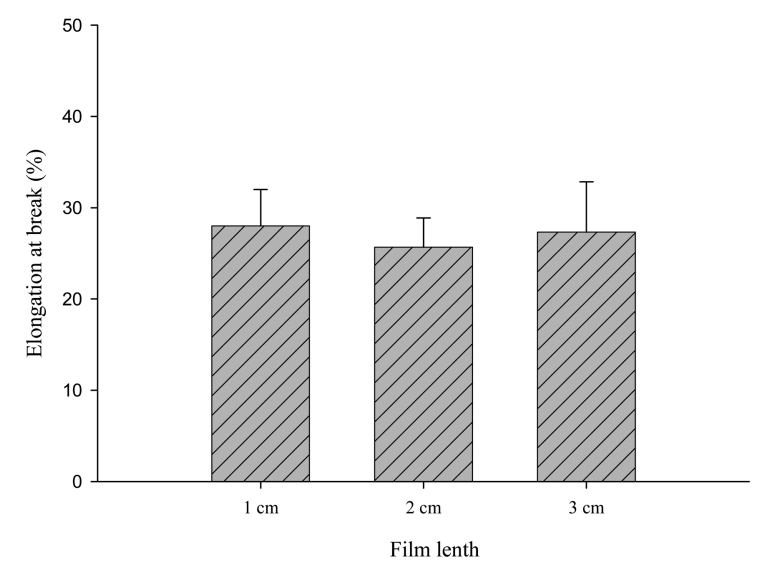

Fig. 4. Effect of film length on the elastic property of the PLGA films (Mean \pm S.D., $n=5$ ).

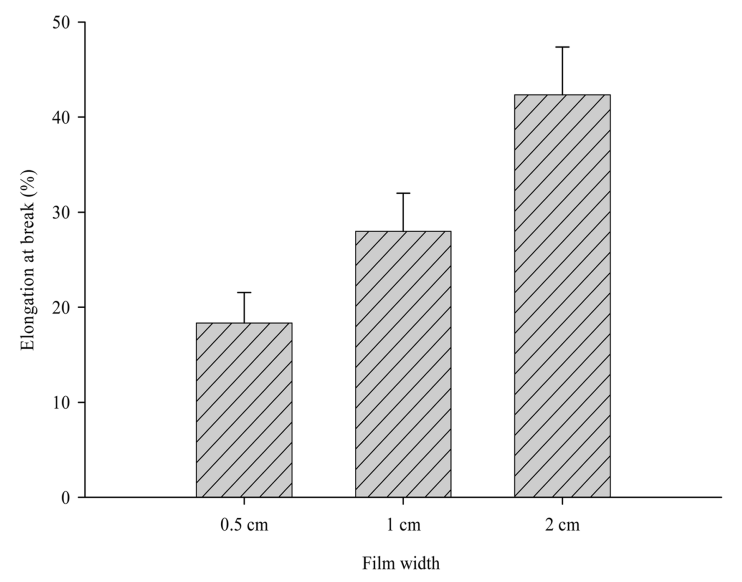

Fig. 5. Effect of film width on the elastic property of the PLGA films (Mean \pm S.D., $n=5$ ).

coated onto the surface of CTR observed by optical microscopy. As can be seen in Figure 8, the plasticizer

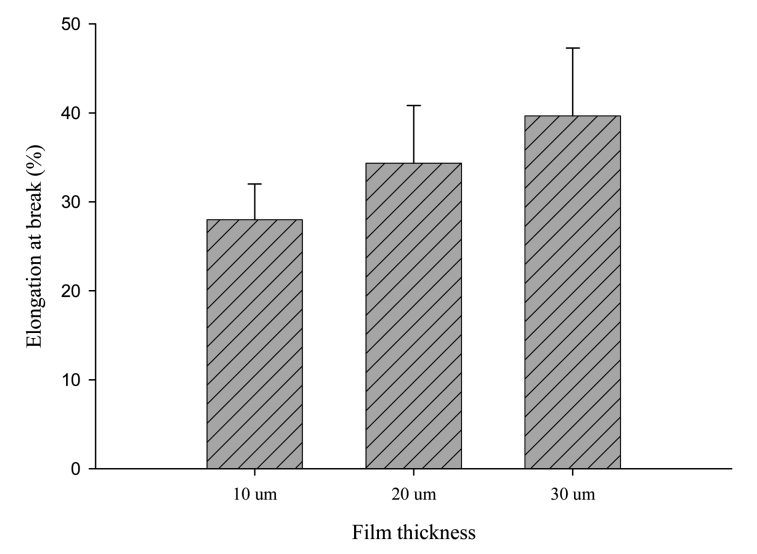

Fig. 6. Effect of film thickness on the elastic property of the PLGA films (Mea $n \pm$ S.D., $n=5$ ).

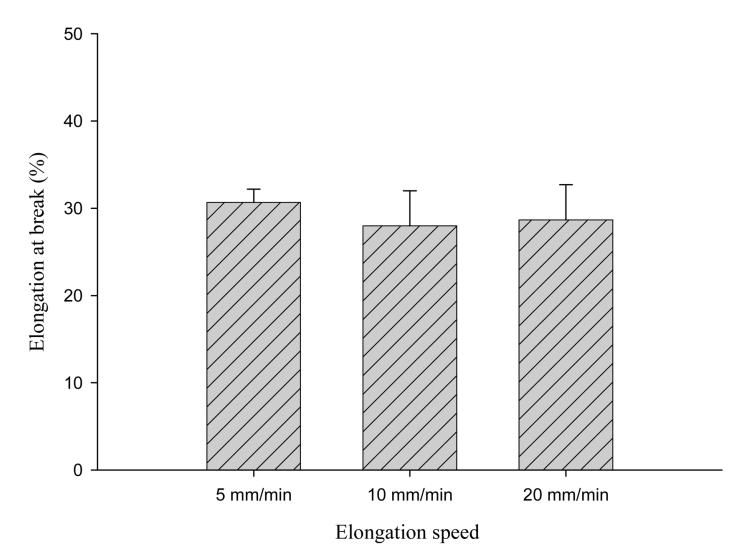

Fig. 7. Effect of elongation speed on the elastic property of the PLGA films (Mean \pm S.D., $n=5$ ). 
A

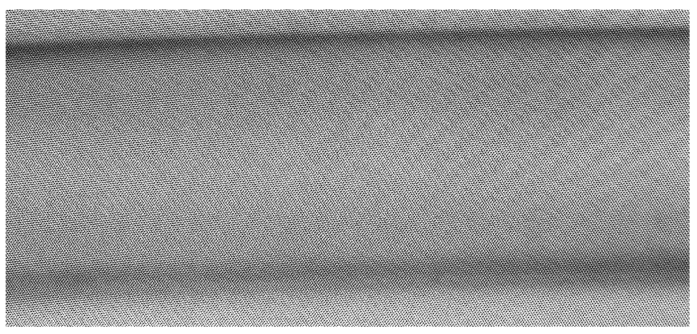

B

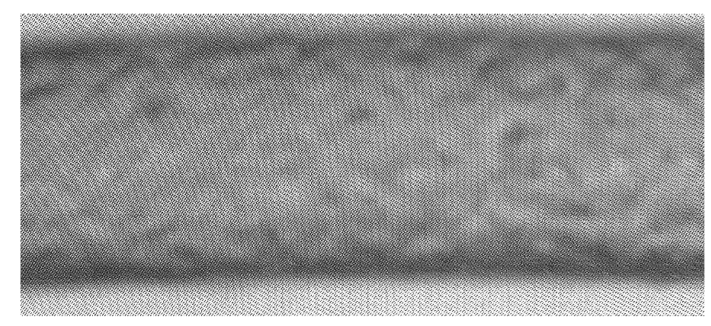

C

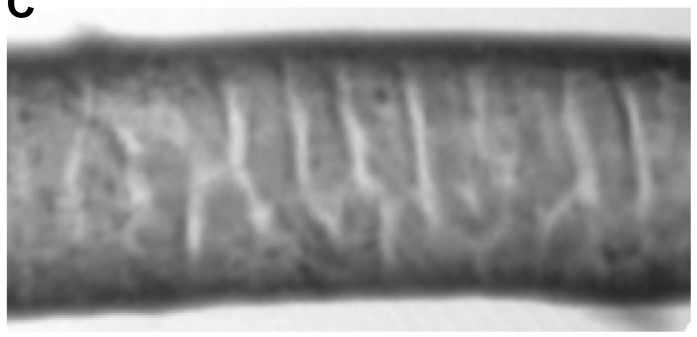

Fig. 8. PLGA film coating on tension ring. (a) Coating free tension ring, (b) PLGA film with $5 \%$ TEC and $2 \%$ dexamethasone and (c) PLGA film with $2 \%$ dexamethasone.

containing films have good flexibility and were not changed in its morphology even after the mechanical stress of ten times of stretching and bending was applied.

In this study, CTR was coated with PLGA by spray coating and evaporation method. The addition of plasticizer, PEG or TEC to PLGA copolymer caused a depression of $T_{\mathrm{g}}$ sufficient to allow for the formation of flexible films at room temperature using PLGA polymer. The elasticity of PLGA films increased with the addition of either PEG or TEC as determined by elongation measurements, demonstrating the plasticizing effects of PEG and TEC. The decrease in elasticity measurements caused by the addition of increasing amounts of dexamethasone to the PLGA/TEC matrix may have been due to a stiffening effect. The increasing of film length and elongation speed had a slight influence on elongation. In conclusion, sufficiently flexible and stable PLGA films capable of being coated onto CTR could be prepared.
This PLGA films can be used as a drug delivery platform for the prevention of PCO.

\section{ACKNOWLEDGEMENTS}

This research was supported by the Chung-Ang University Research Scholarship Grants in 2007.

\section{REFERENCES}

Apple, D. J., Peng, Q., Visessook, N., Werner, L., Pandey, S. K., Escobar, Gomez, M., Ram, J., Whiteside, S. B., Schoderbeck, R., Ready, E. L. and Guindi, A. (2000). Surgical prevention of posterior capsule opacification. Part 1: Progress in eliminating this complication of cataract surgery. J. Cataract Refract. Surg. 26, 180-187.

Bertelmann, E. and Kojetinsky, C. (2001). Posterior capsule opacification and anterior capsule opacification. Curr. Opin. Ophthalmol. 12, 35-40.

Brodbeck, K. J., Pushpala, S. and Mchugh, A. J. (1999). Sustained release of human growth hormone from PLGA solution depots. Pharm. Res. 16, 1825-1829.

Dorta, M. J., Oliva, A., Munguia, O., Llabres, M. and Farina, J. B. (2002). In-vitro release of fluoropyrimidines from PLGA film implants. J. Pharm. Pharmacol. 54, 757-763.

Fernandez, V., Fragoso, M. A., Billotte, C., Lamar, P., Orozco, M. A., Dubovy, S., Willcox, M. and Parel, J. M. (2004). Efficacy of various drugs in the prevention of posterior capsule opacification: experimental study of rabbit eyes. J. Cataract Refract. Surg. 30, 2598-2605.

Ferruti, P., Penco, M., D'addato, P., Ranucci, E. and Deghenghi, R. (1995). Synthesis and properties of novel block copolymers containing poly(lactic-glycolic acid) and poly(ethyleneglycol) segments. Biomaterials 16, 1423-1428.

Gumusderelioglu, M. and Deniz, G. (2000). Sustained release of mitomycin-C from poly(DL-lactide) /poly(DL-lactide-co-glycolide) films. J. Biomater. Sci. Polym. Ed. 11, 1039-1150.

Ismail, M. M., Alio, J. L. and Ruiz Moreno, J. M. (1996). Prevention of secondary cataract by antimitotic drugs: experimental study. Ophthalmic Res. 28, 64-69.

Kranz, H., Ubrich, N., Maincent, P. and Bodmeier, R. (2000). Physicomechanical properties of biodegradable poly(D,L-lactide) and poly(D,L-lactide-co-glycolide) films in the dry and wet states. J. Pharm. Sci. 89, 1558-1566.

Legler, U. F., Apple, D. J., Assia, E. I., Bluestein, E. C., Castaneda, V. E. and Mowbray, S. L. (1993). Inhibition of posterior capsule opacification: the effect of colchicines in a sustained drug delivery system. J. Cataract Refract. Surg. 19, 462-470.

Painter, P. C. and Coleman, M. M. (1997). Fundamentals of polymer science, an introductory text. 2 ed. CRC press., New York.

Pandey, S. K., Cochener, B., Apple, D. J., Colin, J., Werner, L., Bougaran, R., Trivedi, R. H., Macky, T. A. and Izak, A. M. (2002). Intracapsular ring sustained 5-fluorouracil delivery system for the prevention of posterior capsule opacification in rabbits: a histological study. J. Cataract Refract. Surg. 28, 
139-148.

Peng, Q., Apple, D. J., Visessook, N., Werner, L., Pandey, S. K., Escobar-Gomez, M., Schoderbek, R. and Guindi, A. (2000). Surgical prevention of posterior capsule opacification. Part 2: Enhancement of cortical cleanup by focusing on hydrodissection. J. Cataract Refract. Surg. 26, 188-197.

Peng, Q., Visessook, N., Apple, D. J., Pandey, S. K., Werner, L., Escobar-Gomez, M., Schoderbek, R., Solomon, K. D. and Guindi, A. (2000). Surgical prevention of posterior capsule opacification. Part 3: Intraocular lens optic barrier effect as a second line of defense. J. Cataract. Refract. Surg. 26, 198213.

Power, W. J., Neylan, D. and Collum, L. M. (1994). Daunomycin as an inhibitor of human lens epithelial cell proliferation in culture. J. Cataract. Refract. Surg. 20, 287-290.

Ruiz, J. M., Medrano, M. and Alio, J. L. (1990). Inhibition of posterior capsule opacification by 5 -fluorouracil in rabbits. Ophthalmic Res. 22, 201-208.

Tetz, M. R., Ries, M. W., Lucas, C., Stricker, H. and Volcker, H. E. (1996). Inhibition of posterior capsule opacification by an intraocular-lens-bound sustained drug delivery system: an experimental animal study and literature review. J. Cataract. Refract. Surg. 22. 1070-1078.

Webber, W. L., Lago, F., Thanos, C. and Mathiowitz, E. (1998). Characterization of soluble, salt-loaded, degradable PLGA films and their release of tetracycline. J. Biomed. Mater. Res. 41, 18-29. 